\title{
Simulation of diesel engine emissions on the example of Fiat Panda in the NEDC test
}

\author{
Katarzyna Botwinska ${ }^{1,}$, Remigiusz Mruk $^{2}$, Jacek Słoma ${ }^{3}$, Karol Tucki ${ }^{4}$ and Mateusz Zaleski ${ }^{5}$ \\ 1,2,3,4,5 Warsaw University Of Life Sciences, Faculty of Production Engineering, Department of Production Organization and \\ Engineering, Nowoursynowska 164, Warsaw, Poland
}

\begin{abstract}
Road transport may be deemed a strategic branch of modern economy. Unfortunately, a rapid increase in the number of on-road motor vehicles entails some negative consequences as well, for instance, excessive concentration of exhausts produced by engines which results in deterioration of air quality. EURO emission standards which define acceptable limits for exhaust emissions of power units is an example of an activity performed in attempt to improve air quality. The EURO standard defines permissible amount of exhausts produced by a vehicle. Presently new units are examined through NEDC test. For the purpose of this thesis, a virtual test stand in a form of a computer simulation of a chassis dynamometer was used to simulate emission of a diesel engine (compression-ignition engine) in the NEDC test. Actual parameters of the 1.3 MultiJet engine of the Fiat Panda passenger car of 2014 were applied in the model. The simulation was carried out in the Matlab Simulink environment. The simulation model of the Fiat Panda passenger car enables the designation of the emission waveform for all test stages which corresponds to the values received during an approval test in real-life conditions.
\end{abstract}

\section{Introduction}

Air pollution caused by excessive exhaust emission from vehicle engines constitutes a serious problem, which has been growing for years. Transport-related contamination is the most severe within the area of urban agglomerations where the traffic density is definitely the highest [1]. The improvement of road infrastructure, wide availability of vehicles and relatively low prices of used cars result in a sharp increase in the number of onroad cars both in Poland and within the area of the European Community $[1,2]$. The problem lies in the age and technical condition of motor vehicles present on roads. Unfortunately, low prices and average level of wealth of society contribute to the increase of the number of vehicles in poor technical condition which frequently fail to meet emission standards provided for their years of production [3]. Internal combustion engines, powered with petroleum-derived fuels, emit a lot of harmful substances having negative, direct and indirect, influence on live organisms. Harmful substances produced by internal combustion engines of power units include: hydrocarbons, nitrous oxides, carbon oxides, sulphur oxides, particulates, aldehydes and heavy metals. Such substances are toxic to the natural environment, therefore, the need to improve air quality is more and more emphasised [2].

European emission limits are legal regulations, which define acceptable amounts of particular components of exhausts. The standards apply both to petrol and diesel engines. The first emission standard, Euro 1, was introduced in 1993 and it established the emission level for passenger cars as well as passenger and light trucks [1]. The currently binding standard is Euro VI which was introduced by the Regulation (EC) no 715/2007 of the European Parliament and of the Council of 20 June 2007. NEDC (New European Driving Cycle) test is closely related to the standard. It is a binding approval test detecting average fuel consumption of the vehicle and the emission of carbon dioxide and harmful substances (CO, NOx, HC, PM). It is the Euro VI standard, which determines permissible exhaust limits. Currently, every new vehicle which is to be accepted as roadworthy has to undergo such test and receive an approval certificate. This certificate is a prerequisite for roadworthiness [4].

The test lasts 18 minutes and 40 seconds in total and is divided into two parts: urban driving cycle and extraurban driving cycle. The urban driving cycle includes four repeated cycles in which the vehicle is accelerated to the speeds of 15,32 and $50 \mathrm{~km} / \mathrm{h}$, then it is stopped for a specific time. The distance of approximately $4 \mathrm{~km}$ is covered in this cycle, and the average speed amounts to $18.35 \mathrm{~km} / \mathrm{h}$. The total pausing time of the car is over 3 minutes, during which the manual gearbox is in the neutral position with clutch engaged. This stage is supposed to represent movement of the vehicle in urban agglomerations. After that, the next, extra-urban stage begins in which the vehicle is accelerated in turn to the speeds of 70,100 and $120 \mathrm{~km} / \mathrm{h}$. The entire stage lasts 6 minutes and 40 seconds, the vehicle is not stopped but it is decelerated to $50 \mathrm{~km} / \mathrm{h}$. The distance covered in this

\footnotetext{
Corresponding author: katarzyna botwinska@sggw.pl
} 
part is about $7 \mathrm{~km}[5,6]$. The test is performed in laboratory conditions on a specially prepared chassis dynamometer. It allows the simulation of specific engine loads resulting from the stages of the test. The stand is fitted with control and measurement instruments, which among other functions, enable the measurement of the amounts of substances in produced exhausts [4].

\subsection{The aims and scope of the study}

This thesis is aimed at recreating the NEDC test of a selected passenger car. For that purpose, a computer simulation was used which reflects the cooperation between a chassis dynamometer and a model vehicle according to the assumed research cycle. Therefore, the objective of the thesis was to prepare a simulation model of a chassis dynamometer and simulation of exhaust emission of a diesel engine of a selected Fiat Panda passenger car. The scope of the project included the construction of the aforementioned model and the analysis of the obtained results.

\section{Materials and methods}

\subsection{The object of research}

In the simulation the parameters of the 1.3 MultiJet II 16 $\mathrm{v}, 70 \mathrm{~kW}$ engine of Fiat Panda Easy passenger car of 2014 were applied. It is a power unit which conforms to the highest level of the emission standard Euro VI. According to manufacturing specifications the values of fuel combustion for the said engine are: in the urban cycle $4.7 \mathrm{l} / 100 \mathrm{~km}$, in the extra-urban cycle $3.51 / 100 \mathrm{~km}$ and in the mixed cycle $4,71 / 100 \mathrm{~km} . \mathrm{CO}_{2}$ emission in the mixed cycle amounts to $104[\mathrm{~g} / \mathrm{km}]$ [7]. Table 1 demonstrates specifications of the model engine.

Table 1. Specification of 1.3 MultiJet II 16v, $70 \mathrm{~kW}$ engine.

\begin{tabular}{|l|l|}
\hline Parameter & Value \\
\hline Capacity & $1248 \mathrm{~cm} 3$ \\
\hline Maximum power & $55 \mathrm{~kW}(75 \mathrm{KM})$ at $4000[\mathrm{rpm}]$ \\
\hline Maximum torque & $190 \mathrm{~N} \cdot \mathrm{m}$ at $1500[\mathrm{rpm}]$ \\
\hline Generation & $\begin{array}{l}\text { MultiJet II fitted with diesel particulate } \\
\text { filter (DPF) }\end{array}$ \\
\hline $\begin{array}{l}\text { Arrangement of } \\
\text { cylinders }\end{array}$ & line \\
\hline $\begin{array}{l}\text { Number of } \\
\text { cylinders }\end{array}$ & 4 \\
\hline Injections & $\begin{array}{l}\text { Direct MultiJet “Common Rail” controlled } \\
\text { electronically with a turbocharger and } \\
\text { intercooler }\end{array}$ \\
\hline
\end{tabular}

\subsection{Prepared simulation}

Simulation models were created in Matlab Simulink environment. They were developed on the basis of documentation containing requirements for the NEDC test $[5,6]$ and they allowed to obtain information about the options for chassis dynamometer selection and to carry out simulation of exhaust emission of the Fiat Panda car with the MultiJet engine.
To ensure that the simulation is run properly, standard data for the NEDC test was supplemented with information allowing the control of the signal of the engaged gear, the signal of engagement / disengagement of the clutch and signal of the time controlling the simulation which allows the program to perform all key activities according to the test schedule. Thus, in order to obtain a set of gear values in the gearbox in the form of integers, characteristic points for the manipulation of the signal of the gear number and clutch engagement were established for particular stages of the NEDC test for urban and extra-urban cycles. The prepared data controlling the simulation for the NEDC test was entered into the simulation environment as data sets for the tool enabling the creation of continuous waveforms based on characteristic points $[8,9]$. Fig. 1 below depicts the view of waveforms.
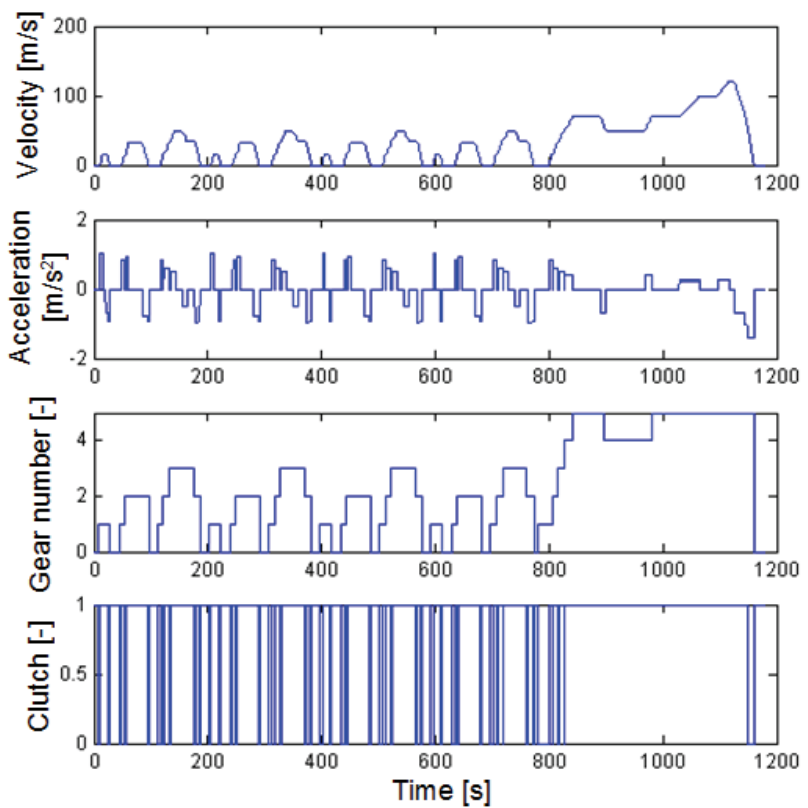

Fig. 1. Component for entering a data set with the view of the introduced control signals in the simulation project of the NEDC test.

The component was entered into the simulation model from which the signals of particular control values for further model elements were then derived. Using the vehicle velocity signal, the "Derivative" component was used to generate acceleration signal necessary for further calculations of the inertia forces of the chassis dynamometer. For that purpose, the following mathematical correlation was used:

$$
a(t)=\frac{d v(t)}{d t}\left[\frac{m}{s^{2}}\right]
$$

Where:

$a(t)$ - acceleration $\left(\mathrm{m} / \mathrm{s}^{2}\right)$,

$v(t)$ - car velocity $(\mathrm{m} / \mathrm{s})$.

Apart from calculation components, the fragment of the model contains "NEDC diagram" element depicting the generated control waveform. The individual parts of the simulation model were built basis on the mathematical reliance contained in the literature sources [10 - 11]. 
Fig. 2 below presents the fragment of the model responsible for the generation of signals controlling the test.

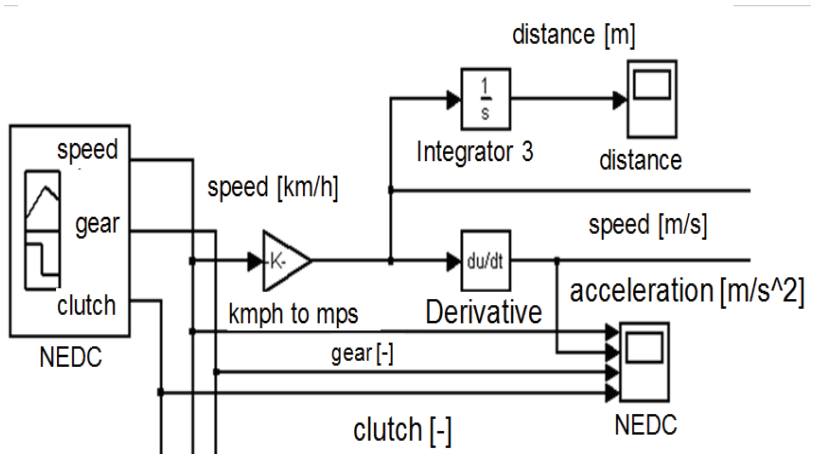

Fig 2. Fragment of the model responsible for the generation of signals controlling the test.

Then a fragment of the model responsible for the determination of the internal friction value of the chassis dynamometer was constructed according to the following correlation:

$$
F_{T}(t)=a+b v(t)^{2}
$$

Where:

$F_{T}(t)$ - load from the friction process absorbed by the chassis dynamometer $(\mathrm{N})$,

$a$ - value equal to the rolling resistance $(\mathrm{N})$,

$b$ - value equal to the air drag coefficient $\left(\mathrm{N} /(\mathrm{km} / \mathrm{h})^{2}\right)$,

$v(t)$ - velocity $(\mathrm{km} / \mathrm{h})$.

Forces generated by the dynamometer related to the required mass inertia during the vehicle velocity changes were determined pursuant to the following correlation [10]:

$$
F_{m}(t)=m \frac{d v(t)}{d t}
$$

Where:

$F_{m}(t)$ - inertia load absorbed by the chassis dynamometer $(\mathrm{N})$, $m$ - Equivalent inertia $(\mathrm{kg})$,

$v(t)$ - velocity $(\mathrm{km} / \mathrm{h})$

The simulation involved matrix calculations which enable the simultaneous generation of many cases of the dynamometer configuration for the selected car mass. In the above correlation specific parameters of the chassis dynamometer included in [6] were used. Table 2 presents the applied correlations.

Table 2. Configuration set of the chassis dynamometer

\begin{tabular}{|c|c|}
\hline $\begin{array}{l}\text { Vehicle reference mass (RM) } \\
(\mathrm{kg})\end{array}$ & Equivalent inertia \\
\hline $965<\mathrm{RM} \leq 1080$ & 1020 \\
\hline $\begin{array}{l}\text { Power and load absorbed by the } \\
\text { dynamometer at } 80 \mathrm{~km} / \mathrm{h}\end{array}$ & $\begin{array}{l}\text { Road load } \\
\text { coefficient }\end{array}$ \\
\hline 270 & 270 \\
\hline
\end{tabular}
selected for the simulation.
In order to acquire information allowing the selection of chassis dynamometer elements responsible for generation of load in the simulation, components were used to calculate temporary value of the power from the car wheels or provided to the system to obtain characteristics of velocity changes in compliance with the guidelines. Temporary power value was calculated from the following correlation which also included a matrix calculus:

$$
P(t)=F(t) v(t)
$$

Where:

$P(t)$ - temporary power value $(\mathrm{W})$,

$F(t)$ - force generated on the dynamometer $(\mathrm{N})$,

$v(t)$ - velocity $(\mathrm{km} / \mathrm{h})$.

Fig. 3 below shows the fragment of the model determining the above values:

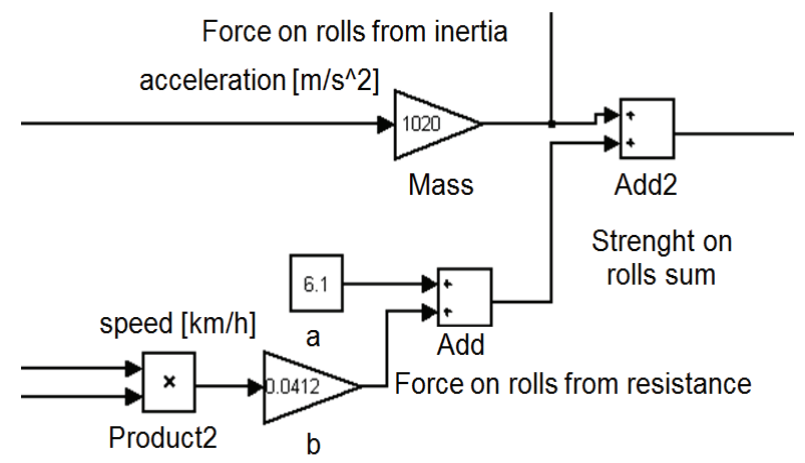

Fig. 3. Fragment of the simulation model responsible for the calculation of the internal friction forces, inertia forces, temporary power of the chassis dynamometer in the NEDC test.

The next step was to create a simulation model of the NEDC test for the configuration of the chassis dynamometer compliant with the parameters of Fiat Panda with the 1.3 MultiJet engine. Fig. 4 below depicts a fragment of the simulation model responsible for the calculation of the rotational speed of vehicle wheels, gearbox ratio, engine rotational speed $\omega e$ and engine torque $\mathrm{Me}$. Those parameters are necessary to establish temporary emission rates of selected exhaust components. For that purpose, the following mathematical correlation was used:

$$
\begin{gathered}
M e=\left(F_{T}+F_{m}\right) \cdot R \cdot \operatorname{Tr} \cdot C[N \cdot m] \\
\omega e=\frac{v(t)}{R} \cdot T \omega \cdot C\left[\frac{\mathrm{rad}}{\mathrm{s}}\right]
\end{gathered}
$$

Where:

$R$ - wheel radius [m],

$\mathrm{Tr}$ - Transmission ratio of the drive system for the torque (0 $1 / 13.46 ; 1 / 7.05 ; 1 / 4.55 ; 1 / 3.24 ; 1 / 2.42][-])$,

$C$ - Clutch engagement signal $(0,1[-])$,

$v(t)$ - Temporary vehicle velocity in the NEDC test,

$T \omega$ - Transmission ratio of the drive system for the rotational speed $(0 ; 13.46 ; 7.05 ; 4.55 ; 3.24 ; 2.42][-])$. 
Below Fig. 4 shows a fragment of the simulation responsible for the calculation of the rotational speed of vehicle wheels, gearbox ratio, engine rotational speed and engine torque in the NEDC test.

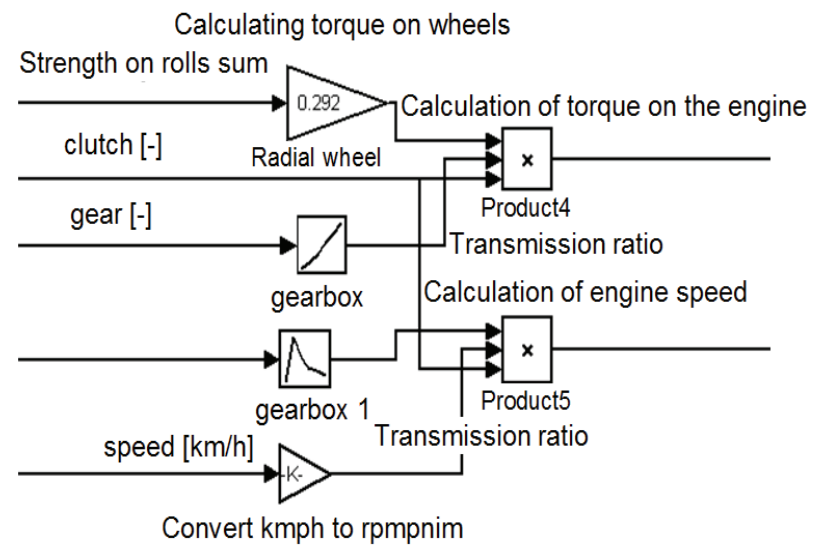

Fig. 4. Fragment of the simulation responsible for the calculation of the rotational speed of vehicle wheels, gearbox ratio, engine rotational speed and engine torque in the NEDC test.

Simulation based on instantaneous values: engine speed, engine torque and fuel and air consumption characteristics of the engine as a function of speed and torque, calculates the instantaneous fuel and air streams fed to the engine in the NEDC test. The simulation uses the mathematical formulas presented below:

$$
\begin{aligned}
\text { air } & =f_{\text {air }}(\omega e, M e)\left[\frac{g}{s}\right] \\
\text { fuel } & =f_{\text {fuel }}(\omega e, M e)\left[\frac{g}{s}\right]
\end{aligned}
$$

where:

$f_{\text {air }}, f_{\text {fuel }}$ - Function of air, fuel consumption depending on the rotational speed and torque $[\mathrm{g} / \mathrm{s}]$

Below Fig. 5 shows a fragment of the model that calculates instantaneous air and fuel streams to the engine in the NEDC test.

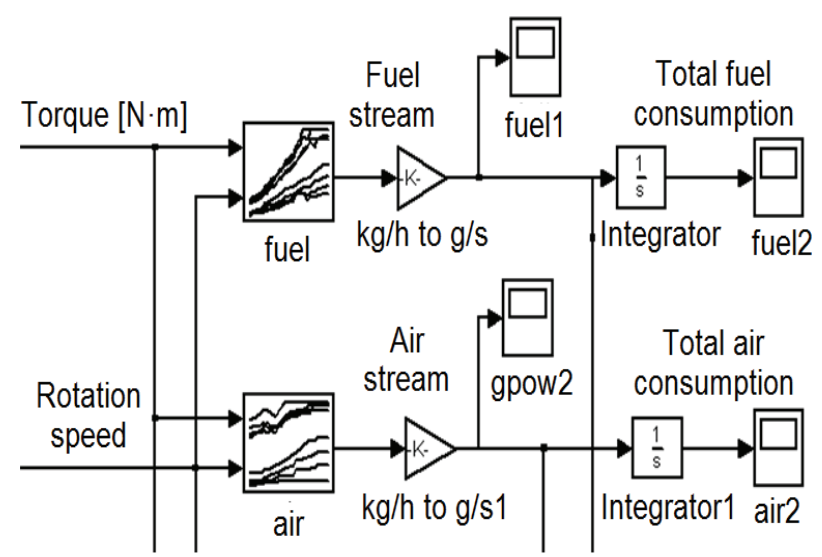

Fig. 5. Fragment of the model responsible for the calculation of the temporary values of the air and fuel streams in the NEDC test.
Additionally, the fragment of the model responsible for the calculation of the temporary values of the streams of selected exhaust components is presented below. It includes fuel consumption fuel $[\mathrm{g} / \mathrm{s}]$ and air consumption air $[\mathrm{g} / \mathrm{s}]$ in the function of the engine rotational speed $\omega S[\mathrm{rpm}]$ and torque produced by the engine $M s[\mathrm{~N} \cdot \mathrm{m}]$, however, for the diagram legibility purposes, the mentioned calculation fragments were omitted in the below fragment.

$$
\begin{aligned}
& \dot{C O}=f_{C O}(\omega s, M s) \cdot(\text { aì }+f \dot{u} e l)\left[\frac{g}{s}\right] \\
& \dot{C O} 2=f_{C O 2}(\omega s, M s) \cdot(\text { ai } r+f \dot{u} e l)\left[\frac{g}{s}\right] \\
& N \dot{O} x=f_{N O x}(\omega s, M s) \cdot(\text { air }+f \dot{u} e l)\left[\frac{g}{s}\right]
\end{aligned}
$$

Where:

$f_{\mathrm{CO}}, f_{\mathrm{CO} 2}, f_{\mathrm{NOx}}$ - Function of the carbon monoxide, carbon dioxide, nitrogen oxides content of the exhaust gases depending on the rotational speed and torque [m\%], $\omega S$ - Engine rotational speed $[\mathrm{rad} / \mathrm{s}]$,

$M s$ - Engine torque $[\mathrm{N} \cdot \mathrm{m}]$ ),

air, fuel - Air, fuel stream $[\mathrm{g} / \mathrm{s}]$.

Fig. 6 shows a fragment of the model responsible for the calculation of the temporary values of the streams of selected exhaust components in the NEDC test.

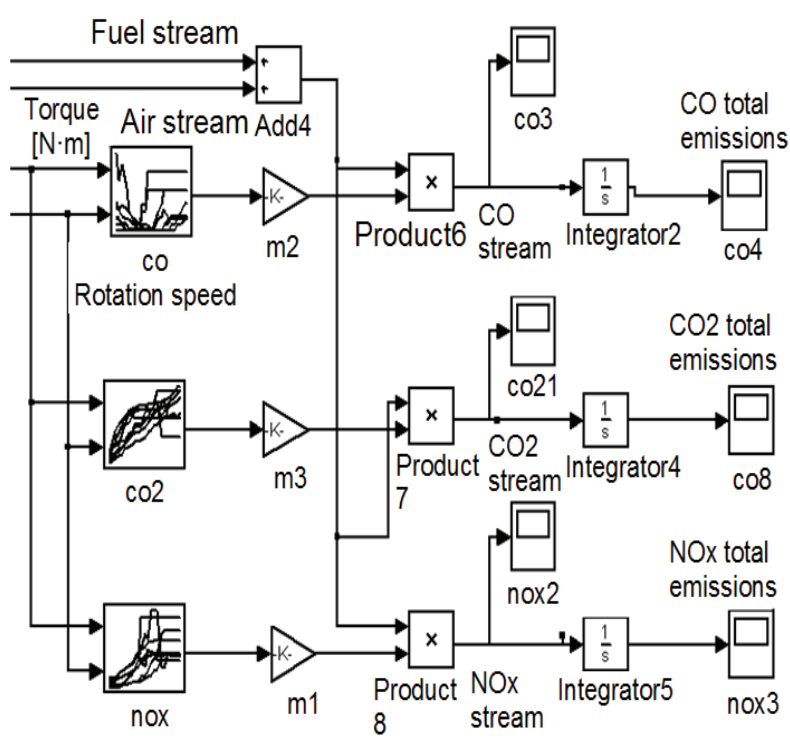

Fig. 6. Fragment of the model responsible for the calculation of the temporary values of the streams of selected exhaust components in the NEDC test.

\section{Results and discussion}

As a result of the simulation of operation of the 1.3 MultiJet engine within the NEDC test, the waveforms of stream $[\mathrm{g} / \mathrm{s}]$ and consumption $[\mathrm{s}]$ of the following media were obtained: fuel and air. The waveforms are depicted below. Fig. 7 shows changes in the fuel stream $[\mathrm{g} / \mathrm{s}]$ and fuel consumption [s] during the simulation. 

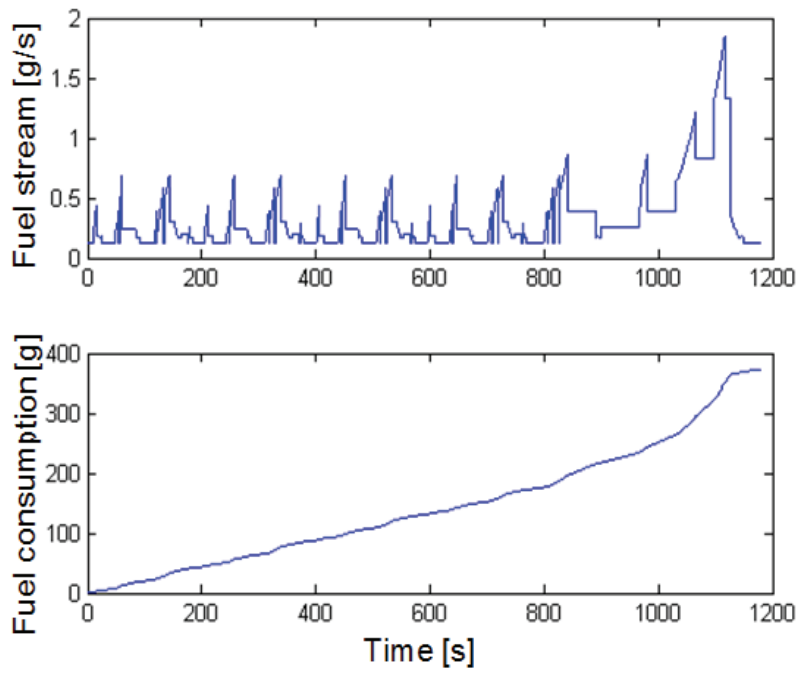

Fig. 7. Changes in the fuel stream $[\mathrm{g} / \mathrm{s}]$ and fuel consumption [s] during the simulation.

Fig. 8 shows changes in the air stream $[\mathrm{g} / \mathrm{s}]$ and air consumption $[\mathrm{s}]$ during the simulation.
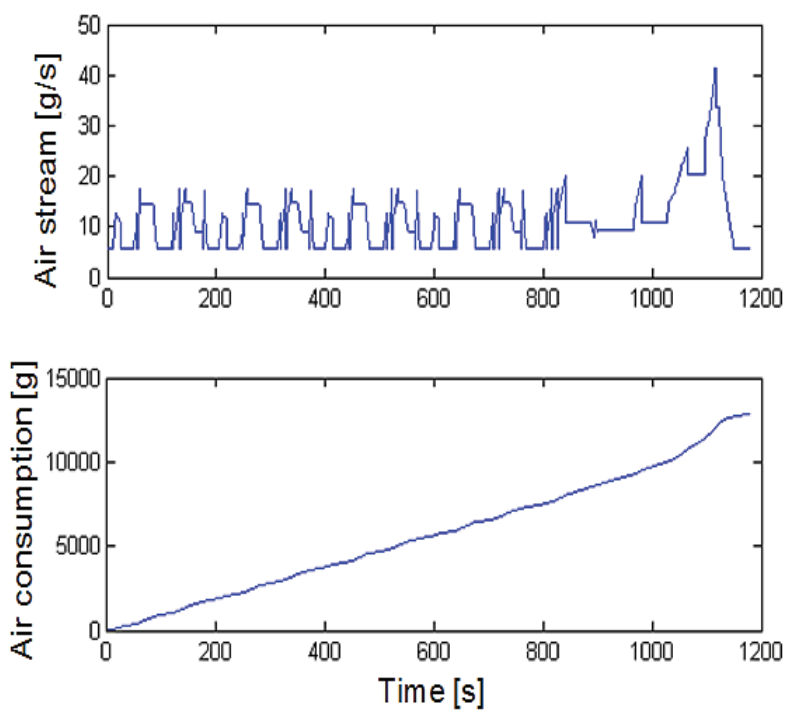

Fig. 8. Changes in the air stream $[\mathrm{g} / \mathrm{s}]$ and air consumption $[\mathrm{s}]$ during the simulation.

As a result of the simulation of operation and emission of the 1.3 MultiJet engine within the NEDC test, the waveforms of stream $[\mathrm{g} / \mathrm{s}]$ and emission $[\mathrm{g}]$ of the following substances were obtained: carbon oxide $\mathrm{CO}$, carbon dioxide $\mathrm{CO}_{2}$ and nitrogen oxides $\mathrm{NO}_{\mathrm{x}}$. The obtained streams of fuel and air streams converge to the engine work during the NEDC test. There were analogies between these parameters and vehicle speed at a given test point. Based on the similarities with scientific sources about the NEDC test, waveforms can be considered valid. The course of the carbon monoxide stream changes with the speed of the vehicle. In the first phase of the 'urban' test, a cyclical increase in the carbon monoxide content can be observed. Maximum values characterize the fastest vehicle speed at any given time for the urban phase. The value of the parameter close to zero corresponds to the stopping the vehicle. In the second extra-urban phase, two points with the highest concentration can be seen, which means the maximum speed for this phase. In the extra-urban cycle, the carbon monoxide content is lower than in the urban cycle. Fig. 9 shows changes in the stream $[\mathrm{g} / \mathrm{s}]$ and emission $[\mathrm{g}]$ of carbon oxide $\mathrm{CO}$ during the simulation.
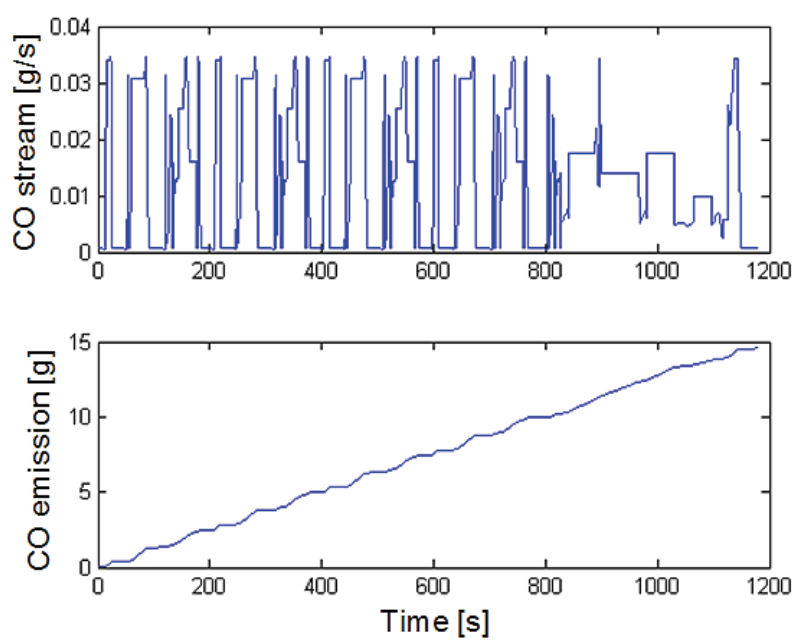

Fig. 9. Changes in the stream $[\mathrm{g} / \mathrm{s}]$ and emission $[\mathrm{g}]$ of carbon oxide $\mathrm{CO}$ during the simulation.

The course of carbon dioxide also changes with the speed of the vehicle. The increase in concentration is proportional to the increase in speed. Compared to the course of carbon monoxide, however, there is a dramatic increase in the concentration for the In the extra-urban cycle phase. Fig. 10 shows changes in the stream $[\mathrm{g} / \mathrm{s}]$ and emission $[\mathrm{g}$ ] of carbon dioxide $\mathrm{CO} 2$ during the simulation.
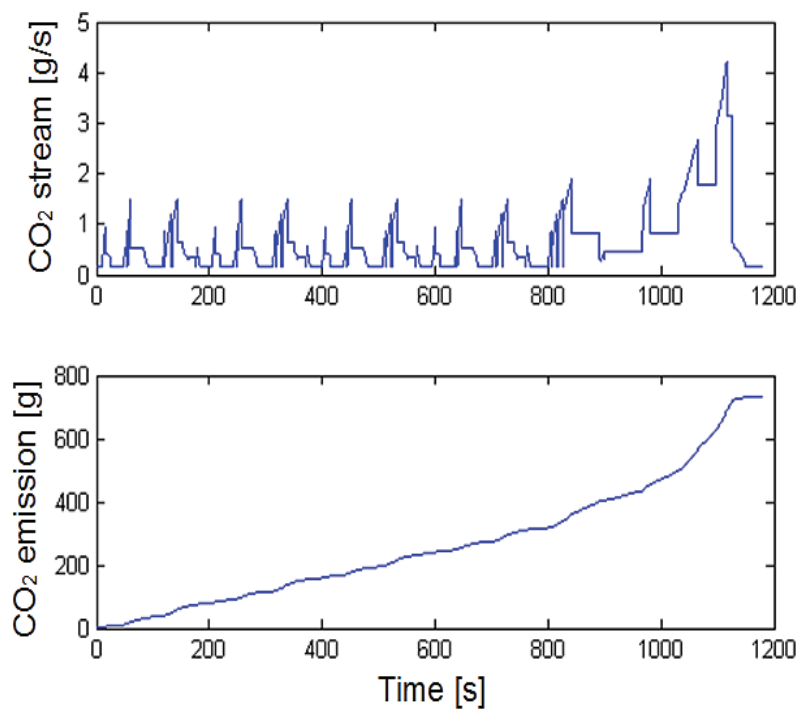

Fig. 10. Changes in the stream $[\mathrm{g} / \mathrm{s}]$ and emission $[\mathrm{g}]$ of carbon dioxide $\mathrm{CO}_{2}$ during the simulation.

Based on the results of the emission of nitrogen oxides, their concentration was highest with sudden increase in vehicle speed. The content of nitrogen oxides in the exhaust gas is, however, much lower than that of carbon mono and dioxide. Fig. 11 shows changes in the stream $[\mathrm{g} / \mathrm{s}]$ and emission $[\mathrm{g}]$ of carbon oxide $\mathrm{CO}$ during the simulation. 

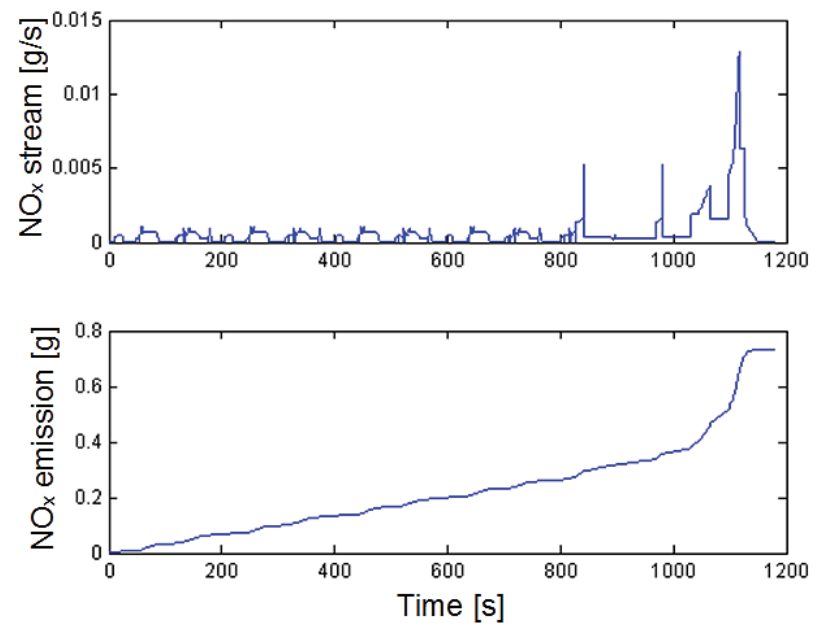

Fig. 11 Changes in the stream $[\mathrm{g} / \mathrm{s}]$ and emission $[\mathrm{g}]$ of nitrogen oxides $\mathrm{NO}_{\mathrm{x}}$ during the simulation.

\section{Conclusions}

The following conclusions may be drawn from the analysis of the prepared simulation model, obtained simulation results and professional literature:

- Matlab Simulink environment facilitates the creation of models and simulation of dynamic elements operation without the need to use complicated mathematical correlations;

- The developed simulation model provided temporary waveforms the total power for the simulation process. Such waveforms enable the determination of the maximum power a vehicle should be loaded with to have proper waveforms of velocity and may constitute the basis for the selection of the brake (in the case of the set with the highest vehicle mass for the NEDC test the value equals to $54 \mathrm{~kW}$ );

- Simulation model for Fiat Panda 1.3 MultiJet provides not only the temporary waveforms of emission for particular test stages but also cumulated waveforms the value of which corresponds to the real processes of the approval tests;

- Developed simulation models may be the basis for the creation of real systems for chassis dynamometer control with the simulation of mass inertia.

\section{References}

1. I. Czapliński, R. Smolec, Autobusy: technika, eksploatacja, systemy transportowe 17 (2016).

2. E. Trzensik, M. Światłoń, Zesz. Nauk. Polit. Śl. (2011).

3. M. Witaszek, K. Witaszek,. Zesz. Nauk. Polit. Śl. Transport (2015).

4. J. Merkisz, M. Andrzejewski, J. Pielecha, Combust. Engines 50 (2011).

5. Barlow, T. J., Latham, S., McCrae, I. S., \& Boulter, P. G., TRL Pub. Proj. Rep. (2009)

6. Regulation No 83 of the Economic Commission for Europe of the United Nations (UNECE).
7. http://cenniki.fiat.pl/fiat/download/fiat/katalog/panda /katalog/nowa panda_katalog.pdf

8. B. Mrozek, Z. Mrozek, PLJ (1998)

9. T. Kumar, OUP (2011)

10. W. Serdecki, Poznan Univ. of Technol (2012)

11. A. Ambrozik, T. Ambrozik, D. Kurczyński, Post. Nauk. i Tech., (2012) 